\title{
Red cell distribution width in patients with HIV infection
}

\author{
María L. Gallego, Isabel A. Pérez-Hernández, Rosario Palacios*, Josefa Ruiz-Morales, \\ Enrique Nuño, Manuel Márquez, Jesús Santos \\ Unidad de Gestión Clínica de Enfermedades Infecciosas, Hospital Universitario Virgen de la Victoria, Málaga, Spain \\ Email: ${ }^{*}$ med006809@saludalia.com
}

Received 24 January 2012; revised 3 February 2012; accepted 14 February 2012

\begin{abstract}
Objective: To examine the association between elevated levels of red cell distribution width (RDW) and cardiovascular risk factors (CVRF) and metabolic syndrome (MS) in HIV-patients. Methods: Cross-sectional study including all asymptomatic HIV-outpatients under follow-up during 2007. Patients completed a questionnaire about CVRF, underwent a physical examination, and an 8-hour fasting blood analysis. Elevated RDW was defined as $\geq 75^{\text {th }}$ percentile. Patients with and without an elevated RDW were compared. Results: 666 patients $(79.3 \%$ men) were included: mean age 44.7 years, mean CD4 506/ $\mathrm{mm}^{3}$ and $87.5 \%$ on antiretroviral therapy $(85.3 \%$ with undetectable viral load). Mean RDW was $13.7 \%$ (range: $7.7 \%-33.6 \% ; 75^{\text {th }}$ percentile, $14.1 \%$ ). The prevalence per quartile of MS was $15.7 \%, 9.3 \%$, $18.8 \%$ and $16.6 \%$ and of patients with CVRF $>20 \%$ was $8.4 \%, 4.0 \%, 4.4 \%$, and $6.4 \%$, respectively $(p>$ $0.05) ; 23.4 \%$ of the patients had an elevated RDW $(>14.1 \%)$. The top percentile of RDW was associated with AIDS (OR 1.6; 95\% CI, 1.0 - 2.4; $p=0.02)$, detectable viral load (OR 1.5; 95\% CI, $1.01-2.4 ; \mathrm{p}=$ 0.04) and hypertension (OR 2.3; 95\% CI, 1.4 - 4.0; p $=0.001)$. Conclusions: In HIV-outpatients, higher RDW is related with detectable viral load and with AIDS. Although it was associated with hypertension, we found no relation with MS nor with higher cardiovascular risk.
\end{abstract}

Keywords: HIV; Red Cell Distribution Width; Cardiovascular Risk; Metabolic Syndrome

\section{INTRODUCTION}

Red cell distribution width (RDW), which indicates the degree of anisocytosis, is currently considered a new marker of inflammatory activity [1]. A rise in this parameter has been related with cardiovascular disease, the metabolic syndrome (MS) and increased morbidity and mortality in persons with prior cardiovascular disease as

${ }^{*}$ Corresponding author. well as in the general population [2-8]. In patients infected with the human immunodeficiency virus (HIV) the prevalence of cardiovascular risk factors (CVRF) is greater than in the general population, with the resulting increase in the incidence of cardiovascular events $[9,10]$. Both the HIV infection itself and the antiretroviral treatment taken play a role in the development of cardiovascular events in this population [11-13]. In addition, these patients also have a higher prevalence of the MS $[14,15]$. The aim of this study was to examine the possible association between elevated levels of RDW and CVRF and MS in patients with HIV infection.

\section{PATIENTS AND METHODS}

We undertook an observational, cross-sectional study including all patients with HIV infection under follow-up at the Infectious Diseases Unit of Virgen de la Victoria Hospital, Malaga, during 2007. The patients, who were all asymptomatic, completed a questionnaire about CVRF and underwent a physical examination with measurements of anthropometric data, blood pressure and an 8-hour fasting blood analysis that included the lipid and glucose profile. The 10-year cardiovascular risk was determined form the Framingham equation and the diagnosis of MS was based on the criteria of the National Cholesterol Education Program [16]. The RDW was considered to be elevated when it was $\geq 75^{\text {th }}$ percentile. The continuous variables were expressed as the mean (range and interquartile range) and the categorical variables as an absolute number (\%). The characteristics of the patients with an elevated RDW were compared to those of the patients without an elevated RDW. Comparison of the continuous variables was done with the Student $t$ test or the Mann-Whitney U test if they did not follow a normal distribution. The degree of association of categorical variables was measured by the $\chi^{2}$ test with Yates correction or Fisher's exact test. The statistical analyses were done using SPSS 17.0 (Chicago, IL).

\section{RESULTS}

The study included 666 patients $(79.3 \%$ men), and the 
mean age was 44.7 years. The mean CD4 lymphocyte count was $506 \mathrm{~mm}^{3}$ and $87.5 \%$ were on antiretroviral therapy, $290(43.5 \%)$ with non-nucleoside reverse transcriptase inhibitors and $258(38.7 \%)$ with protease inhibitors. The use of nucleoside reverse transcriptase inhibitors were as follows: lamivudine 289 (43.3\%), abacavir $279(41.8 \%)$, tenofovir $250(37.5 \%)$, emtricitabine $181(27.1 \%)$, didanosine $120(18.0 \%)$, zidovudine 64 (9.6\%), and stavudine 27 (4.0\%). 85.3\% of patients on antiretroviral therapy had an undetectable viral load. The mean RDW was $13.7 \%$ (range: $7.7 \%-33.6 \% ; 75^{\text {th }}$ percentile, $14.1 \%$ ). The prevalence per quartile of MS was $15.7 \%, 9.3 \%, 18.8 \%$ and $16.6 \%$ and the prevalence of patients with CVRF $>20 \%$ was $8.4 \%, 4.0 \%, 4.4 \%$, and $6.4 \%$, respectively ( $p>0.05$ ); $23.4 \%$ of the patients had a RCDW above the $75^{\text {th }}$ percentile $(>14.1 \%)$. Table 1 shows the comparison between the patients with and without an elevated RDW. In the multivariate analysis, the top percentile of RDW was associated with a diagnosis of AIDS (OR 1.6; 95\% CI, $1.0-2.4 ; \mathrm{p}=0.02$ ), having a detectable HIV viral load (OR 1.5; 95\% CI, 1.01 - 2.4; $\mathrm{p}=0.04)$ and hypertension (OR 2.3; 95\% CI, $1.4-4.0 ; \mathrm{p}$ $=0.001$ ).

\section{DISCUSSION}

In this cohort of patients with HIV infection and a good clinical and immune-virological status, an elevated RDW was associated with having AIDS, a detectable HIV viral load and hypertension. No association was found with a higher prevalence of CVRF or the presence of MS.

Although the exact pathophysiological mechanism

Table 1. Characteristics of the 666 study patients and comparison between those with the highest quartile of elevated red cell distribution width $(\mathrm{RCDW})(>14.1 \%)$ and those below this quartile.

\begin{tabular}{|c|c|c|c|}
\hline Variables & $\mathrm{RCDW}>14.1 \%(\mathrm{n}=156)$ & $\mathrm{RCDW}<14.1 \%(\mathrm{n}=510)$ & $\mathrm{p}$ \\
\hline Male sex & $109(69.8)$ & $419(82.1)$ & 0.001 \\
\hline Age (years) & $44.6(38.6-49.0)$ & $44.7(38.6-49.1)$ & 0.8 \\
\hline $\operatorname{BMI}\left(\mathrm{kg} / \mathrm{m}^{2}\right)$ & $24.3(21.6-26.5)$ & $24.3(21.9-26.3)$ & 0.9 \\
\hline Smoker & $99(63.4)$ & $339(66.4)$ & 0.3 \\
\hline HIV sexual risk & $105(67.3)$ & $354(69.4)$ & 0.5 \\
\hline Months with HIV & $122.5(62.5-174.5)$ & $120.6(59.9-170.2)$ & 0.7 \\
\hline AIDS & $70(44.8)$ & $129(25.2)$ & 0.03 \\
\hline ART & $132(84.6)$ & $443(86.8)$ & 0.3 \\
\hline CD4 (cells/mL) & $483(218-687)$ & $513(332-654)$ & 0.2 \\
\hline CD4 $<350$ cells $/ \mathrm{mL}$ & $56(35.8)$ & $136(26.6)$ & 0.03 \\
\hline CD4 nadir (cells/mL) & $205(43-272)$ & $210(70-313)$ & 0.7 \\
\hline \multicolumn{4}{|l|}{ HIV viral load } \\
\hline$<50 \operatorname{cop} / \mathrm{mL}^{*}$ & $103(66.0)$ & $388(76.0)$ & 0.01 \\
\hline Mean RCDW (\%) & $15.5(14.4-15.8)$ & $12.3(11.6-13.2)$ & 0.001 \\
\hline Diabetes & $18(11.5)$ & $73(14.3)$ & 0.4 \\
\hline Hypertension & $30(19.2)$ & $54(10.5)$ & 0.006 \\
\hline Hypertriglyceridemia & $57(36.5)$ & $199(39.0)$ & 0.6 \\
\hline Low HDL cholesterol & $82(52.5)$ & 214 (41.9) & 0.02 \\
\hline Central obesity & $23(14.7)$ & $54(10.5)$ & 0.1 \\
\hline MS & $26(16.6)$ & $74(14.5)$ & 0.5 \\
\hline CVR at 10 years $(\%)$ & $6.17(1-8)$ & $6.88(1-11)$ & 0.2 \\
\hline $\mathrm{CVR}>10 \%$ & $33(21.1)$ & $144(28.2)$ & 0.09 \\
\hline
\end{tabular}

RCDW: red cell distribution width. BMI: body mass index. ART: antiretroviral therapy. MS: metabolic syndrome. CVR: cardiovascular risk. ${ }^{*}$ Patients on ART. The quantitative variables are expressed as the mean (IQR) and the qualitative variables as $\mathrm{n}(\%)$. 
concerning the association between RDW, cardiovascular disease and morbidity and mortality is unknown, any systemic factor that alters red cell homeostasis, such as inflammation or oxidative stress, may play a role [7]. The relation found in this study between an elevated RDW, the presence of AIDS and, particularly, a detectable viral load, could be explained by the inflammatory state induced by HIV replication, as well as by the disease itself. This inflammatory state prevents red cell maturation, producing anisocytosis, as has been suggested in other studies in the non-HIV population, independently of the existence or otherwise of anemia $[2,6]$. The relation between an elevated RDW and hypertension has been reported in patients with coronary disease [2], as well as in a recent study in hypertensive persons. An association has also been found between an elevated RDW and carotid artery atherosclerosis [17]. Unlike the findings of Sánchez-Chaparro et al. [3] in the general population, an elevated RCDW in our series of HIV patients was not associated with the presence of MS. Finally, it has been reported that RDW may be modified after starting treatment with thymidin nucleoside reverse transcriptase inhibitors [18], which are the type of these drugs less used in our series.

Nevertheless, the data from the various studies are not all in agreement, possibly due in part to the different methods used and the different characteristics of the study patients. For instance, the mean age in our series was lower than that of most earlier studies.

The cross-sectional design of our study, with its possible residual confounding factors, is a limitation. In addition, no measurements were made of vitamin B12, iron or folic acid, which can normally modify the RDW, though the data were adjusted for the hemoglobin and the mean corpuscular volume, which are surrogate markers of these parameters.

This study provides the first data concerning the possible importance of the RDW in patients with HIV infection, highlighting its relation with a poor control of the disease, though we found no association with CVRF.

In summary, the RDW, which is usually determined with the blood cell count and involves no extra cost, can be considered an inflammatory marker which might help improve the risk stratification in HIV-infected patients.

\section{REFERENCES}

[1] Lippi, G., Targher, G., Montagnana, M., Salvagno, G.L., Zoppini, G. and Guidi, G.C. (2009) Relation between red blood cell distribution width and inflammatory biomarkers in a large cohort of unselected outpatients. Archives of Pathology and Laboratory Medicine, 133, 628632.

[2] Tonelli, M., Sacks, F., Arnold, M., Moyle, L., Davis, B. and Pfeffer, M. (2008) Relation between red blood cell distribution width and cardiovascular event rate in people with coronary disease. Circulation, 117, 163-168. doi:10.1161/CIRCULATIONAHA.107.727545

[3] Sánchez-Chaparro, M.A, Calvo-Bonacho, E., GonzálezQuintela, A., et al. (2010) Higher red blood cell distribution width is associated with the metabolic syndrome: Results of the ibermutuamur cardiovascular risk assessment study. Diabetes Care, 33, e40. doi:10.2337/dc09-1707

[4] Felker, G.M., Allen, L.A., Pocock, S.J., et al. (2007) Red cell distribution width as a novel prognostic marker in heart failure: Data from the CHARM Program and the Duke Databank. Journal of the American College of Cardiology, 50, 40-47. doi:10.1016/j.jacc.2007.02.067

[5] Patel, K.V., Semba, R.D., Ferrucci, L., et al. (2010) Red cell distribution width and mortality in older adults: A meta-analysis. Journals of Gerontology Series A: Biological Sciences and Medical Sciences, 65, 258-265.

[6] Chen, P.C., Sung, F.C., Chien, K.L., Hsu, H.C., Su, T.C. and Lee, Y.T. (2010) Red blood cell distribution width and risk of cardiovascular events and mortality in a community cohort in Taiwan. American Journal of Epidemiology, 171, 214-220. doi:10.1093/aje/kwp360

[7] Patel, K.V., Ferrucci, L., Ershler, W.B., Longo, D.L. and Guralnik, J.M. (2009) Red cell distribution width and the risk of death in middle-aged and older adults. Archives of Internal Medicine, 169, 515-523. doi:10.1001/archinternmed.2009.11

[8] Ye, Z., Smith, D. and Kullo, I.J. (2011) Usefulness of red cell distribution width to predict mortality in patients with peripheral artery disease. American Journal of Cardiology, 107, 1241-1245. doi:10.1016/j.amjcard.2010.12.023

[9] Friis-Møller, N., Reiss, P., Sabin, C.A., et al. (2007) Class of antiretroviral drugs and the risk of myocardial infarction. The New England Journal of Medicine, 356, 1723-1735. doi:10.1056/NEJMoa062744

[10] Santos, J., Palacios, R., González, M., Ruiz, J. and Márquez, M. (2005) Atherogenic lipid profile and cardiovascular risk factors in HIV-infected patients (Nétar Study). International Journal of STD \& AIDS, 16, $677-$ 680. doi: $10.1258 / 095646205774357398$

[11] Baker, J.V., Neuhaus, J., Duprez, D., et al. (2011) Changes in inflammatory and coagulation biomarkers: A randomized comparison of immediate versus deferred antiretroviral therapy in patients with HIV infection. Journal of Infectious Diseases, 56, 36-43.

[12] Calmy, A., Gayet-Ageron, A., Montecucco, F., et al. (2009) HIV increases markers of cardiovascular risk: Results of a randomized, treatment interruption trial. AIDS, 23, 929-939. doi:10.1097/QAD.0b013e32832995fa

[13] Worm, S.W., Sabin, C., Weber, R., et al. (2010) Risk of myocardial infarction in patients with HIV infection exposed to specific individual antiretroviral drugs from the 3 major drug classes: The data collection on adverse events of anti-HIV drugs (D:A:D) study. Journal of Infectious Diseases, 201, 318-330. doi:10.1086/649897

[14] Gazzaruso, C., Sacchi, P., Garzaniti, A., Fratino, P., 
Bruno, R. and Filice, G. (2002) Prevalence of metabolic syndrome among HIV patients. Diabetes Care, 25, 12531254. doi:10.2337/diacare.25.7.1253

[15] Palacios, R., Santos, J., González, M., Ruiz, J. and Márquez, M. (2007) Incidence and prevalence of the metabolic syndrome in a cohort of naïve HIV-infected patients: Prospective analysis at 48 weeks of highly active antiretroviral therapy. International Journal of STD \& AIDS, 18, 184-187. doi:10.1258/095646207780132415

[16] National Cholesterol Education program (NCEP) Expert Panel on Detection, Evaluation, and Treatment of High Blood Cholesterol in Adults (Adult Treatment Panel III) (2002) Third Report of the National Cholesterol Educa- tion Program (NCEP) Expert Panel on Detection, Evaluation, and Treatment of High Blood Cholesterol in Adults (Adult Treatment Panel III) final report. Circulation, 106, 3143-3421.

[17] Wen, Y. (2010) High red blood cell distribution width is closely associated with risk of carotid artery atherosclerosis in patients with hypertension. Experimental \& Clinical Cardiology, 15, 37-40.

[18] Rivas, P., Górgolas, M. and Fernández-Guerrero, M.L. (2005) Zidovudine and red-cell distribution width. The New England Journal of Medicine, 352, 2141-2142. doi:10.1056/NEJM200505193522023 